\title{
TRANSPARENCIA, ACCESO A LA INFORMACIÓN Y UNIVERSIDAD PÚBLICA AUTÓNOMA
}

\author{
TRANSPARENCE, INFORMATION ACCESS \\ AND AUTONOMUS PUBLIC UNIVERSITY
}

Jorge CARPIZO

RESUMEN: Armonizar el derecho de acceso a la información pública y el derecho constitucional de autonomía de las universidades públicas es el principal objetivo de este artículo. Para ello, el autor analiza, por un lado, la autonomía universitaria en su vertiente de derecho constitucional y, por otro, hace un esbozo histórico del derecho a la información, la transparencia y el acceso a la documentación pública. Una premisa fundamental del autor consiste en la inexistencia de contradicciones entre estos dos derechos constitucionales, toda vez que ambos persiguen la misma finalidad: proteger y hacer efectiva la dignidad humana. Por tal motivo, concluye haciendo una propuesta, que llama debatible, de lo que a su juicio son 23 consideraciones para armonizar los derechos en cuestión.

Palabras clave: universidades públicas, autonomía universitaria, derecho a la información, transparencia pública, derechos constitucionales.
ABSTRACT: Harmonize between the right to public information access and the constitutional right of autonomy of public universities is the principal objective of this article. For that, the author analyzes, for one side, the university autonomy in its constitutional right view, and for the other, makes an historical sketch on the right to information, the transparence and the access to public documentation. A fundamental premise of the author consists in the inexistence of contradictions between these two constitutional rights, as far as those purse the same purpose: to protect and make effective human dignity. For that reason, he concludes making a proposition, which he calls discussable, of which, in his judgment, are 23 considerations to harmonize the rights in issue.

Descriptors: Public Universities, University Autonomy, Right to Information, Public Transparence, Constitutional Rights. 


\section{INTRODUCCIÓN}

Este ensayo busca aportar algunas consideraciones que puedan ser útiles para armonizar el derecho de acceso a la información pública y el derecho constitucional de la autonomía de las universidades públicas. Como el lector se percatará, una de las tesis vertebrales del ensayo es que entre los derechos constitucionales no existen incompatibilidades ni contradicciones, sino que es necesario encontrar su debida armonización dentro del marco de cada Constitución y de las fuentes del derecho constitucional, como son la jurisprudencia y el derecho internacional de los derechos humanos.

Por la razón anterior, la primera cuestión que se aborda es la naturaleza de la autonomía universitaria como derecho constitucional, los diversos aspectos que la integran y los alcances de la misma.

A continuación se ofrece un esbozo del derecho a la información, la transparencia y el acceso a la documentación pública, desde la reforma constitucional de 1977, la ley federal respectiva de 2002 y la adición al artículo 6o. constitucional en 2007.

La tercera parte del ensayo versa sobra las razones y argumentos que fundamentan la inexistencia de contradicciones, conflictos o enfrentamientos entre los derechos constitucionales; en forma especial se destaca que todos ellos persiguen la misma finalidad: proteger y hacer efectiva la dignidad humana. En consecuencia, cuando se presenta una aparente contradicción entre ellos, la labor debe ser de armonización y de compatibilidad.

Con los elementos anteriores, como base y fundamento, se entra de lleno a la parte medular del ensayo. Después de haber examinado los diversos reglamentos y acuerdos de transparencia y acceso a la información pública de las universidades públicas autónomas de México, se exponen 23 consideraciones que persiguen el propósito de colaborar a la debida armonización de los derechos constitucionales objeto de este ensayo. Son consideraciones, y soy consciente de ello, de las que algunas pueden prestarse a debate. Mediante éste —al cual estamos acostumbrados los universitarios - se precisan las ideas, y así se avanza en la protección, defensa y armonización de los derechos que la Constitución consagra. 


\section{LA AUTONOMÍA UNIVERSITARIA COMO DERECHO CONSTITUCIONAL}

1. El 9 de junio de 1980 se publicó en el Diario Oficial de la Federación la adición de un párrafo al artículo 3o. constitucional, y se cambió el número de la última fracción del mencionado artículo.

El actual párrafo VII del artículo 3o. expresa que:

Las universidades y las demás instituciones de educación superior a las que la ley otorgue autonomía, tendrán la facultad y la responsabilidad de gobernarse a sí mismas; realizarán sus fines de educar, investigar y difundir la cultura de acuerdo con los principios de este artículo, respetando la libertad de cátedra e investigación y de libre examen y discusión de las ideas; determinarán sus planes y programas; fijarán los términos de ingreso, promoción y permanencia de su personal académico; y administrarán su patrimonio. Las relaciones laborales, tanto del personal académico como del administrativo, se normarán por el apartado A del artículo 123 de esta Constitución, en los términos y con las modalidades que establezca la Ley Federal del Trabajo conforme a las características propias de un trabajo especial, de manera que concuerden con la autonomía, la libertad de cátedra e investigación y los fines de las instituciones a que esta fracción se refiere...

La fracción en comentario enumera las características de la autonomía universitaria y precisa algunos aspectos de las relaciones laborales en las universidades públicas autónomas.

Ahora bien, el texto en cita se refiere únicamente a las universidades e instituciones de educación superior de carácter público, en virtud de que éstas son las que se crean por medio de una ley, de acuerdo con la mención que se hace en la propia fracción. En consecuencia, las disposiciones de la misma no alcanzan a las universidades e instituciones de educación superior privadas.

La autonomía de las universidades se reconoce en la ley que crea y regula cada universidad, y no en la fracción constitucional. Así, una universidad o institución pública de educación superior será autónoma, o no, de acuerdo con lo que disponga su ley orgánica.

2. El principio de autonomía universitaria ha sido muy discutido, y aunque sus alcances se han precisado en las respectivas leyes orgánicas, intereses políticos lo han tratado de desvirtuar, como en el caso de quienes identifican autonomía con extraterritorialidad. Lo anterior es tan im- 
portante que la exposición de motivos de la iniciativa presidencial se refiere expresamente a este problema:

Es compromiso permanente del Estado respetar irrestrictamente la autonomía para que las instituciones de cultura superior se organicen, administren y funcionen libremente, y sean sustento de las libertades, jamás como fórmula de enfeudamiento que implique un derecho territorial por encima de las facultades primigenias del Estado.

Estoy de acuerdo con la idea anterior; las universidades están encuadradas dentro del orden jurídico de México y no es posible pensar que pudieran quedar al margen de él. Lo que acontece es que el Estado está obligado a ofrecer educación superior y, por razones técnicas, aunadas a principios democráticos y de libertad, decide, en algunos casos, no impartir educación superior directamente, sino a través de organismos a los que les reconoce una característica especial: su autonomía. Es este principio el que distingue e imprime un sello especial a esos organismos.

3. La autonomía se otorga a las universidades para que puedan cumplir sus funciones sin injerencias externas y ajenas que le dificultarían el cumplimiento de aquéllas conforme a los principios de excelencia académica y proyección social, para que la educación que se imparta se encuentre libre de todo dogmatismo o ideología. ${ }^{1}$

Esa educación debe formar estupendos profesionistas, simultáneamente con una concepción social de la existencia. Su preparación es para que se realice como persona, al mismo tiempo que sea útil a la sociedad a la que pertenece y se debe. La universidad pública y autónoma debe combatir las ideas egoístas e individualistas. La universidad pública y autónoma está inmersa en la sociedad, la cual la sostiene y con la que tiene que colaborar para mejorarla. La universidad pública y autónoma cumple con una función social de especial relevancia. ${ }^{2}$

4. La fracción mencionada señala los fines de las universidades y de las instituciones de educación superior: educar, investigar y difundir la

1 González Pérez, Luis Raúl y Guadarrama López, Enrique, Autonomía universitaria y Universidad pública. El autogobierno universitario, México, UNAM, Oficina del Abogado General, 2009, p. 25.

2 Véase Valadés, Diego, "Derecho a la educación”, Enciclopedia Jurídica Mexicana, México, UNAM, Instituto de Investigaciones Jurídicas y Editorial Porrúa, 2004, t. VIII, p. 796. 
cultura. Estos son los fines que se han considerado tienen las universidades. Una universidad sin investigación será sólo una escuela grande en donde se repiten los conocimientos; una universidad debe ser algo más: la búsqueda constante para incrementar y enriquecer los conocimientos, el lugar donde se crea la cultura y se le difunde para que llegue a la población del país. Expresa la fracción que estos fines los debe realizar de acuerdo con los principios del propio artículo 3o. constitucional, es decir, esos fines se desarrollarán en forma democrática, nacional, con conciencia social, de acuerdo con la dignidad humana y fomentando el amor a la patria y a la conciencia de la solidaridad internacional en la independencia y en la justicia.

5. Los principios integrantes de la autonomía derivados del texto constitucional son: ${ }^{3}$

a) Académica: i) implica que sus fines los realiza de acuerdo con la libertad de cátedra e investigación y el libre examen y discusión de las ideas; ii) la determinación de sus planes y programas, y iii) la fijación de los términos de ingreso, promoción y permanencia del personal académico.

Estos principios son muy importantes: a la libertad de cátedra e investigación incluso se le ha identificado con la propia autonomía. ${ }^{4}$ Donde no existe libertad para enseñar y para investigar, los conocimientos no pueden avanzar. Donde existe una "verdad", y no es posible apartarse de ella, el pensamiento fenece y la cultura decae. En la naturaleza misma de las universidades se encuentra la libertad de cátedra y de investigación que, desde luego, presupone el libre examen y discusión de todas las ideas.

Las universidades, a través de sus diversos órganos técnicos, determinan sus planes y programas, qué disciplinas ofrecen, las materias que integran los curricula académicos, qué se debe enseñar en cada materia, los créditos que vale esa materia, etcétera. ${ }^{5}$

3 Pinto Mazal, Jorge, La autonomía universitaria, México, UNAM, Comisión Técnica de Legislación Universitaria, 1974, pp. 19-21, 275 y 276; García Laguardia, Jorge Mario, La autonomía universitaria en América Latina. Mito y realidad, México, UNAM, Comisión Técnica de Estudios y Proyectos Legislativos, 1977, pp. 22-28; Hurtado Márquez, Eugenio, La universidad autónoma: 1929-1944, México, UNAM, Comisión Técnica de Estudios y Proyectos Legislativos, 1976, pp. 135-172.

4 Pinto Mazal, Jorge, op. cit., nota anterior, p. 7.

5 Carpizo, Jorge, "La garantía constitucional de la autonomía universitaria”, Legislación y jurisprudencia, México, UNAM, Instituto de Investigaciones Jurídicas, 1980, 
La calidad y categoría de una universidad y de cómo cumple sus fines, se encuentra en una altísima parte basada en su personal académico y en la preparación y actualización de éste. Luego, las universidades deben tener la certeza de que quienes entran a laborar académicamente pueden hacerlo bien. En otras palabras, el ingreso, promoción y permanencia del personal académico no es sólo una cuestión laboral sino fundamentalmente académica. En esta forma se deja a la precisión de las universidades, a través de sus estatutos y reglamentos, esos aspectos para que se pueda garantizar un alto nivel del personal docente y de investigación.

b) De gobierno: las universidades tienen la facultad y responsabilidad de gobernarse a sí mismas. En esta característica encontramos dos principios: i) nombramientos de sus propias autoridades, y ii) otorgamiento de sus normas.

Los funcionarios universitarios son funcionarios públicos designados por la propia comunidad universitaria, y no por los órganos del gobierno. Entre los funcionarios del gobierno y los universitarios no hay relación de jerarquía sino de respeto mutuo. Las autoridades y funcionarios universitarios deben ser personal que conozca la problemática de las universidades, que posea nivel académico y que sea conocido por la comunidad universitaria. Lo anterior sólo se logrará si la propia comunidad designa a sus autoridades.

Los órganos legislativos expiden las leyes orgánicas en las que se encuentran los principios fundamentales de organización, pero son las propias universidades las que precisan dichos principios y se otorgan sus propios estatutos y reglamentos, como el general, los de admisión, exámenes, revalidación, etcétera. En esta forma, las universidades poseen la facultad de legislación para su ámbito interno. En este aspecto es interesante resaltar que la autonomía universitaria se asemeja a la autonomía de las entidades federativas: la facultad de legislar en el ámbito interno, teniendo como marco una norma de carácter superior, que no se debe contravenir.

c) Económica: consiste en la administración de su patrimonio. Este es un aspecto de particular importancia. Las universidades públicas no pueden cubrir sus necesidades con recursos propios, lo que hace necesario que el Estado les otorgue un subsidio. Recuérdese que las universidades ción y en la ley, México, UNAM, Instituto de Investigaciones Jurídicas, 2005, p. 149. 
cumplen funciones que al Estado corresponden. Luego, el subsidio es una obligación de éste, no un acto gracioso. ${ }^{6}$

No obstante, a través del subsidio el Estado podría, llegado el caso, tratar de influir en las universidades, y es por ello que se ha entendido que la autonomía, desde el punto de vista económico, implica que son las propias universidades las que determinan en qué materias y en qué proporción se gastarán los recursos. En consecuencia, la autonomía económica tiene especial importancia a pesar del otorgamiento de los subsidios. Con los enormes gastos que una universidad pública realiza no es posible que los efectúe con sus propios recursos; luego, autonomía no es sinónimo de autosuficiencia económica.

Las universidades suelen publicar sus estados contables y entregarlos al órgano de fiscalización del Estado como principio de transparencia y rendición de cuentas. El manejo de sus recursos económicos no debe prestarse a duda o suspicacia algunas. La universidad, en este aspecto, debe ser una caja de cristal.

Ahora bien, contempladas las características que configuran el principio de autonomía, debemos examinarlo en su relación con el Estado y de lo cual ya asenté: el Estado es quien expide la ley que crea y organiza en lo general a la universidad, le otorga un subsidio y la universidad cumple con una función social que le corresponde al Estado, pero que éste ha decidido descentralizar para que se realice mejor, y para ello es indispensable la libertad de cátedra y de investigación.

Además, las universidades preparan a los principales cuadros humanos que requiere el sector público, realizan investigación indispensable para el Estado y la sociedad, y en ellas se encuentra la mejor oportunidad para que México vaya consiguiendo cierta independencia científica y tecnológica.

Entonces, dos aspectos quedan claros. El primero, la autoridad universitaria tiene un carácter académico-administrativo y, desde luego, no político-administrativo.

El segundo, en el nombramiento de la autoridad universitaria no debe intervenir ni tener ingerencia alguna autoridad externa. En consecuencia, 
esta última no es competente para opinar, calificar o modificar la designación de la autoridad universitaria. ${ }^{7}$

Las universidades son la conciencia crítica del país, arenas de libertad en donde se examinan y conviven todos los pensamientos y todas las ideologías. Estos aspectos influyen en el sistema político y en el propio Estado.

Las relaciones entre las universidades y el Estado deben ser de mutuo respeto, cada quien debe actuar dentro del campo de atribuciones que le corresponde. El país pierde cuando se quiebran estas relaciones de respeto. Las universidades deben estar comprometidas con los problemas de la nación y deben auxiliar en su solución.

Las universidades en el cumplimiento de sus funciones se encuentran con las siguientes limitaciones: 1. Realizar sus funciones bien y no las que no le corresponden; 2. Respetar el orden jurídico; 3 . Actuar libre y responsablemente, es decir, sin libertinaje ni anarquía, y 4. Los recursos económicos de que disponga, deben ser suficientes para que pueda cumplir adecuadamente con sus fines, a la vez que deben utilizarse con pulcritud y transparencia.

La segunda parte de la fracción constitucional precisa las relaciones laborales. En la exposición de motivos de la iniciativa presidencial se pone de relieve que las precisiones laborales tienen la finalidad de hacer compatibles la autonomía y los fines de las universidades con los derechos laborales de los trabajadores universitarios. Esta ha sido la tesis de la UNAM que recogió la ANUIES y posteriormente el Poder Ejecutivo federal: "El gobierno de la República está persuadido de que estas precisiones auxiliarán a que las universidades cumplan cada día mejor sus finalidades y se superen académicamente para que México pueda lograr su independencia científica y tecnológica".

En una palabra, esta parte de la fracción deslinda lo académico de lo laboral; ${ }^{8}$ así se fortalece la autonomía universitaria.

\footnotetext{
7 González Pérez, Luis Raúl y Guadarrama López, Enrique, op. cit., nota 1, pp. 27 y 28.

8 Dávalos, José, "Las relaciones laborales en el marco de la autonomía universitaria", Cuadernos de Legislación Universitaria, México, UNAM, Dirección General de Estudios de Legislación Universitaria, nueva época, vol. I, núm. 1, 1986, pp. 32-41; Orozco Henríquez, José de Jesús, Régimen de las relaciones colectivas de trabajo en las universidades públicas autónomas, México, UNAM, Instituto de Investigaciones Jurídicas, 1993, pp. 141-142; García Ramírez, Sergio, op. cit., nota 5, pp. 153-158.
} 


\section{EL DERECHO FUNDAMENTAL DE ACCESO}

\section{A LA DOCUMENTACIÓN PÚBLICA}

1. En 1977, dentro del marco de la denominada Reforma Política de ese año, se adicionó el artículo 6o. constitucional con una oración: "El derecho a la información será garantizado por el Estado".

Se entendió que era un nuevo derecho que establecía la Constitución y que era trascendente, de naturaleza individual en virtud de su colocación en la norma suprema, porque se le relacionaba con la libertad de expresión, y es indispensable tener información para ejercer otros derechos. No obstante, el derecho a la información posee una proyección social indudable, debido a que se encuentra indisolublemente unido al interés social y garantiza el pluralismo ideológico de la sociedad. ${ }^{9}$

Asimismo, este derecho influye en la modelación de la opinión pública. En tal virtud, la información debe ser objetiva y no estar sujeta a manipulación. ${ }^{10}$

Este derecho es parte del contenido material de la democracia; en ésta existe publicidad de los actos de autoridades y funcionarios.

La secrecía es propia de la autocracia. La democracia implica transparencia en la información y la rendición de cuentas. Estos aspectos, asimismo, se encuentran íntimamente relacionados.

En una democracia nadie puede ser irresponsable, menos quienes manejan recursos públicos.

Resultaba obvio que el nuevo derecho necesitaba una ley reglamentaria para su ejercicio cabal. Al respecto se realizaron los estudios pertinentes y se concretó un anteproyecto. Sin embargo, los intereses en contra del nuevo derecho consiguieron detenerlo.

Los preceptos constitucionales son autoaplicativos o de eficacia jurídica inmediata; si no, el principio de supremacía constitucional se deteriora: quedaría a voluntad discrecional del Poder Legislativo expedir las normas que hicieran posible el cumplimiento de una disposición constitucional, y con esa actitud se nulificarían derechos contenidos en la Constitución.

9 Reforma Política, México, Gaceta Informativa de la Comisión Federal Electoral, t. I: Audiencias públicas, 1977, p. 243.

10 Reforma Política, México, Gaceta Informativa de la Comisión Federal Electoral, t. III: Reformas a la Constitución, 1978, p. 47. Carpizo, Jorge, Estudios constitucionales, México, Porrúa-UNAM, Instituto de Investigaciones Jurídicas, 2003, pp. 359 y 360. 
No obstante, resulta difícil ejercer algunos derechos establecidos en la Constitución si una norma secundaria no precisa la forma en que habrá de hacerse; uno de éstos es el derecho a la información.

2. En 2002 se publicó la Ley Federal de Transparencia y Acceso a la Información Pública Gubernamental, que fue impulsada por diversos grupos sociales que presentaron la iniciativa al congreso. Comenzaba así la cultura de la transparencia de la función pública. Dicha Ley garantiza el acceso de toda persona a la información en posesión de los poderes federales, los órganos constitucionales autónomos, órganos con autonomía legal, y cualquier otra entidad federal.

Para aplicar y hacer vigentes las normas de la Ley se creó el Instituto Federal de Acceso a la Información Pública (IFAI), como un órgano con autonomía operativa y de decisión. ${ }^{11}$

Con esta Ley se comenzó a quebrar la tradición de secrecía de los poderes federales, especialmente del ejecutivo.

El ejemplo federal de la mencionada Ley fue seguido por las entidades federativas, las cuales también expidieron sus respectivas disposiciones sobre transparencia y acceso a la documentación pública.

3. La discusión y promulgación de la Ley de la Reforma del Estado de abril de $2007^{12}$ aceleró la discusión de una modificación constitucional para garantizar el derecho de acceso a la información, en virtud de que las legislaciones de las entidades federativas sobre la materia eran muy diversas, heterogéneas y desiguales. En algunos casos, más que una garantía a dicho derecho resultaba una restricción al mismo y, en otros, únicamente era una simulación para anularlo de facto.

Además, toda esa heterogeneidad lesionaba el derecho de las personas que solicitaban información, en virtud de que los procedimientos, los límites, la apertura y los documentos disponibles eran de la gama más diversa y variada. Así, un derecho fundamental se protegía en forma por demás desigual, dependiendo de la entidad federativa en la cual se realizaba la solicitud de acceso a la información. Como consecuencia, surgió

11 Instituto Federal de Acceso a la Información Pública, Transparencia, acceso a la información y datos personales, México, IFAI, 2006, 200 pp.

12 Carpizo, Jorge, "La reforma del Estado en 2007 y 2008", Cuestiones Constitucionales. Revista Mexicana de Derecho Constitucional, México, UNAM, Instituto de Investigaciones Jurídicas, 2008, núm. 19, pp. 28 y 29. 
la inquietud de si un derecho fundamental puede diferenciar a los mexicanos por razón del lugar de su nacimiento o residencia.

4. La idea, entonces, concretada en un anteproyecto firmado por varios gobernadores pertenecientes a los tres principales partidos políticos y apoyada por el IFAI, fue y es que la Constitución establezca una serie de principios y bases, que la Federación, los estados y el Distrito Federal habrán de respetar al legislar sobre el derecho de acceso a la información.

Dicha reforma constitucional se publicó en el Diario Oficial de la $\mathrm{Fe}$ deración el 20 de julio de 2007; en la misma se agregan varios párrafos al artículo sexto de la ley fundamental.

5. Los más importantes de esos principios y bases son:

i. Toda la información que producen y en manos de autoridad o entidad federal, estatal o municipal, es pública y sólo puede ser reservada temporalmente por razones de interés público. La persona, si se le niega la información, tiene los medios de defensa para impugnar la decisión del órgano público que se la denegó.

ii. La información respecto a la vida privada y datos personales se encuentra protegida en los términos y excepciones que determine la ley.

iii. Toda persona, sin necesidad de acreditar interés alguno o justificar su utilización, tiene acceso gratuito a la información pública y a sus datos personales.

iv. Se establecen órganos especializados, con autonomía operativa, de gestión y de decisión para la revisión y el aseguramiento de dichos derechos.

v. Las autoridades y entidades correspondientes deben preservar sus documentos en archivos actualizados y habrán de publicar en medios electrónicos sus indicadores de gestión y el ejercicio de los recursos públicos.

6. Ricardo Becerra y Sergio López-Ayllón, dos de los principales especialistas en la materia, cuya participación durante el procedimiento de la reforma al artículo 6o. constitucional fue trascendente, afirman, y con razón, que:

Si se mira bien, si se extraen las consecuencias lógicas y políticas, el nuevo texto de la Constitución implica una auténtica revolución institucional. En 
México, la transparencia ya no puede ser entendida como trámite accesorio, trabajo adicional o monserga diaria para funcionarios, sino que induce otra pauta al trabajo, otra forma de organización administrativa y más allá, un nuevo valor para la política y el servicio público.

Las instituciones gubernamentales deberán "producir" información sobre el ejercicio de los recursos, sobre sus funciones, los resultados que obtienen y las razones de sus decisiones. La mecánica es simple pero subversiva: quedan obligadas a documentar todo acto que derive de sus facultades, competencias y funciones, incluso de los procesos deliberativos. ${ }^{13}$

\section{ENTRE LOS DERECHOS CONSTITUCIONALES NO EXISTEN CONFLICTOS}

1. Todos los derechos humanos son muy importantes; ellos son decenas y decenas. Su finalidad es proteger y hacer efectiva la dignidad humana; luego, entre ellos no puede haber ningún conflicto ni enfrentamiento, sino armonía y compatibilidad, y quienes tienen que precisar estas armonías y compatibilidades son las Constituciones, los tratados internacionales, las leyes y las jurisprudencias. La doctrina otorga elementos para afinar ese método.

¿Y por qué es indispensable que se realice dicha armonía y compatibilidad? Por una razón muy sencilla, pero extraordinariamente importante: para no vulnerar, infringir o anular los derechos y libertades de los otros, en virtud de que los derechos y libertades son para todos y de todos, para y de cada ser humano.

Es decir, es la idea que Emmanuel Kant expresó al manifestar que la libertad de cada uno no debe ser restringida más allá de lo que es necesario para asegurar una libertad igual a todos. O, en otras palabras, es el mismo pensamiento de Karl Popper al afirmar que la paradoja de la libertad ilimitada es que ella conduce a la dominación del más fuerte. ${ }^{14}$

13 Becerra, Ricardo y López-Ayllón, Sergio, "Transparencia: horas decisivas", Reforma, Enfoque, México, 13 de abril de 2008; véase Becerra, Ricardo y Lujambio, Alonso "Por qué constitucionalizar", en López-Ayllón, Sergio (coord.), Democracia, transparencia y Constitución, México, IFAI-UNAM, Instituto de Investigaciones Jurídicas, 2007, pp. 173-197; Gómez Gallardo, Perla y Villanueva, Ernesto, Indicadores de transparencia y reforma del artículo 6o. constitucional, México, Trust, 2007, p. 195.

14 Pigeat, Henri, Médias et déontologie. Règles du jeu ou jeu sans règles, París, Presses Universitaires de France, 1997, pp. 7 y 8. 
Estas ideas están incorporadas en textos legales. Por ejemplo, el artículo 32.2 de la Convención Americana de Derechos Humanos dice: "Los derechos de cada persona están limitados por los derechos de los demás, por la seguridad de todos y por las justas exigencias del bien común, en una sociedad democrática”.

Debo precisar que la tesis de la armonía o armonización de los derechos humanos no es universalmente admitida. Sin embargo, si se examinan con cuidado los pensamientos de autores que hablan de colisiones, conflictos o enfrentamientos entre ellos, veremos que pareciera que algunos tímidamente se van acercando a la idea de la necesaria armonización o delimitación de unos con los otros. ${ }^{15}$

2. Eduardo Novoa afirma que resulta casi contradictorio $-\mathrm{y}$ así me parece- suponer que dos o más derechos humanos puedan entrar en colisión o pugna entre sí, pero que, sin embargo, se dan situaciones en que la vida privada de una persona "choca" con la necesidad de otros de poseer una mayor información sobre lo que acontece en la vida social. Es decir, de acuerdo con su pensamiento se dan casos en los cuales el derecho a la vida privada se presenta como "opuesto" a la libertad de información a la cual tienen derecho los demás miembros de la sociedad. ${ }^{16}$

3. Desde luego, las tesis que se inclinan por las colisiones, conflictos o enfrentamientos entre los derechos humanos encuentran aparentemente un indiscutible ejemplo de ello en la relación que se establece entre el de-

15 El distinguido tratadista español González Pérez, Jesús, La degradación del derecho al honor (honor y libertad de información), Madrid, Civitas, 1993, pp. 37-39, sostiene lo siguiente: "El ejercicio de un derecho fundamental puede dar lugar a colisiones con otros derechos que la Constitución consagra asimismo como fundamentales, que es necesario resolver salvando en lo posible el contenido esencial de cada derecho. Es indudable que el contenido esencial de un derecho - contenido que en todo caso debe respetar su regulación, según el artículo 53.1 de la Constitución- impone límites a su ejercicio, cuando no puede amparar actuaciones que vayan más allá de aquél. Se trata de límites intrínsecos del derecho, distintos a los que pueden venir del ejercicio de otro con el que se entra en colisión. Estamos ante un problema de delimitación y no de limitación.

Cuando el ejercicio de un derecho fundamental dentro de su ámbito propio incide en el ámbito de otro es cuando se produce una colisión, que habrá de resolverse tratando de respetar al máximo el contenido esencial de cada uno y, en tanto no sea posible, dando primacía a uno de ellos. La prioridad puede venir expresamente establecida en el propio texto constitucional".

16 Novoa Monreal, Eduardo, Derecho a la vida privada y libertad de información, México, Siglo XXI, 1981, p. 9. 
recho a la vida privada y el derecho a la información. Si la cuestión no se examina con cuidado sí pareciera que existe ese conflicto, pero si nos auxiliamos con la lupa de las ideas anteriormente expuestas, veremos que ese aparente conflicto es sólo un asunto de armonización de derechos, y desde esta perspectiva no existe jerarquía superior entre los derechos a la vida privada y el derecho a la información, sino que examinándose la causa concreta, el juez decide qué precepto constitucional y legal debe aplicar a dicho asunto. El juez, sin embargo, debe respetar el marco constitucional y legal que armoniza los diversos derechos humanos.

4. La Suprema Corte argentina, en un juicio muy connotado —el de "Campillay"-, asentó en 1986 que la libertad de expresión es la libertad de dar y recibir información, pero que éstas no implican un derecho absoluto, y el legislador, ante los posibles abusos producidos mediante su ejercicio, tipifica diversos delitos penales y establece ilícitos civiles, ya que "el ejercicio del derecho de informar no puede extenderse en detrimento de la necesaria armonía con los restantes derechos constitucionales, entre los que se encuentran el de la integridad moral y el honor de las personas (artículos 14 y 35, Constitución nacional)". ${ }^{17}$

En esta sentencia, la tesis de la armonía de los derechos humanos es muy clara y se encuentra dentro de las grandes corrientes del humanismo occidental. Empero, también se ha considerado que la Suprema Corte argentina, en otros juicios, ha limitado la libertad de prensa para otorgar jerarquía prioritaria al derecho al honor y a la dignidad personal. ${ }^{18}$

Yo no haría el planteamiento de esa manera porque vulnera la esencia de la tesis de la "armonización". Entre los derechos humanos no existen jerarquías, con la única excepción de los derechos no derogables, como son, entre otros, el derecho a la vida, la prohibición a la esclavitud y la prohibición de la tortura y tratos inhumanos. ${ }^{19}$

Lo que acontece, vuelvo a expresarlo, es que el juez aplica los preceptos constitucionales y legales al caso concreto, armonizando dos impor-

17 Citado por Zannoni, Eduardo A. y Bíscaro, Beatriz R., Responsabilidad de los medios de prensa, Buenos Aires, Astrea, 1993, p. 50.

18 Bidart Campos, Germán José, "La evolución constitucional en Argentina entre 1917 y 1987”, El constitucionalismo en las postrimerías del siglo XX. México, UNAM, 1988 , t. III, p. 63.

19 Gómez-Robledo, Alonso, "Protección de la 'privacía' frente al Estado", Diagnóstico genético y derechos humanos. Cuadernos del Núcleo de Estudios Interdisciplinarios en Salud y Derechos Humanos, México, UNAM, 1998, pp. 92 y 93. 
tantísimos derechos humanos: el de la vida privada y el de la libertad de expresión o derecho a la información en su evolución actual. ${ }^{20}$

5. Miguel Urabayen sostiene que entre los derechos a la intimidad y a la información hay que encontrar un equilibrio, porque ambos son de esencial y equivalente importancia, pero de no ponérseles límites, cada uno tratará de anular al otro. De inmediato agrega que como el interés general priva sobre el particular, "podría partirse de la base de que el derecho a la información es la regla y el derecho a la intimidad la excepción". Termina afirmando que hay que examinar cada caso planteado, ${ }^{21}$ que es lo que he venido sosteniendo.

El juez analiza el asunto que se le ha sometido a su consideración y armoniza - equilibra, diría Urabayen - las normas aplicables para que la justicia se realice en el caso concreto, pero sin que uno de esos derechos humanos tenga mayor jerarquía que el otro. El problema - reitero- se circunscribe a decidir cuáles son las normas aplicables a esa causa determinada. Esta labor no es fácil, porque implica la utilización de conocimientos profundos del orden jurídico y de sus técnicas de aplicación.

6. Zannoni y Bíscaro se refieren a los límites internos de la libertad de expresión - la verdad y la actitud del informador hacia la verdad- y a los externos: el establecimiento de adecuados equilibrios si se suscita un "conflicto" con otro u otros derechos fundamentales, como puede acontecer en el caso del derecho a la privacidad o intimidad, que posee igual excelencia y jerarquía formal que aquél. Estos autores precisan que los derechos fundamentales no prevalecen unos sobre los otros, como principio a priori. ${ }^{22}$

7. No cabe ninguna duda que el derecho a la información es una de las bases del sistema democrático, que la sociedad como tal y los individuos deben estar bien informados; con veracidad y objetividad.

No puede existir contradicción entre los derechos humanos, ni uno es de mayor jerarquía que el otro, sino los dos existen y tienen que coexistir para reforzar y fortalecer al ser humano en su dignidad.

20 Carpizo, Jorge, Temas constitucionales, México, Porrúa, UNAM, Instituto de Investigaciones Jurídicas, 2003, pp. 238-242.

21 Urabayen, Miguel, Vida privada e información: un conflicto permanente, Pamplona, Ediciones Universidad de Navarra, 1977, p. 349.

22 Zannoni, Eduardo A. y Bíscaro, Beatriz R., op. cit., nota 17, pp. 63, 64, 88 y 89. 
8. En la mencionada reforma constitucional de 2007 al artículo 6o. de nuestra ley fundamental, resulta claro y no discutible que se incluyó a las universidades públicas autónomas en la expresión "organismo federal, estatal y municipal".

Así, la fracción I de dicho artículo dispone que: "Toda la información en posesión de cualquier autoridad, entidad, órgano y organismo (el énfasis es mío) federal, estatal y municipal, es pública y sólo podrá ser reservada temporalmente por razones de interés público en los términos que fijen las leyes...".

Por el otro lado, existe el derecho a la autonomía para las universidades públicas, cuya respectiva ley las configure con esta protección y derecho constitucional.

De acuerdo con las ideas expuestas en este inciso, no es posible que pueda existir contradicción, jerarquía o conflicto entre los derechos constitucionales de la autonomía universitaria y el acceso a la documentación pública en dichas universidades. En caso de aparente contradicción, resulta necesario armonizar esos dos derechos constitucionales, tan valioso $\mathrm{y}$ trascendente es el uno como el otro.

Las universidades públicas autónomas, en ejercicio de su facultad de otorgarse sus propias disposiciones jurídicas dentro del marco de su Ley Orgánica, han expedido normas para regular el acceso a la información pública que poseen, cuidando de armonizar este derecho con el de la autonomía universitaria.

\section{LA ARMONIZACIÓN ENTRE LA AUTONOMÍA UNIVERSITARIA Y EL ACCESO A LA DOCUMENTACIÓN PÚBLICA}

He examinado los diversos reglamentos y acuerdos de transparencia y acceso a la información pública que actualmente rigen en las universidades públicas autónomas. De ellos he extraído 23 consideraciones que expongo a continuación:

1. En los reglamentos y acuerdos de transparencia y acceso a documentos públicos de las universidades públicas autónomas, es notoria la finalidad de cumplir cabalmente con dichos rubros, que las universidades públicas respeten debidamente las normas legales, y ahora constitucionales, que consagran esos derechos. 
2. No obstante, no puede negarse que existen temas preocupantes en algunos de esos acuerdos o reglamentos. La finalidad tiene que ser la salvaguardia de la autonomía con respeto pleno a la transparencia.

3. Tampoco puede desconocerse que en varias de las leyes correspondientes de los estados surgen problemas, en virtud de que no se han armonizado correctamente los derechos constitucionales relativos a la autonomía universitaria, contenida en el artículo 3o. constitucional, y el derecho a la información y acceso a la documentación pública establecidos en el artículo 60.

Por ejemplo, en algunas leyes se identifica organismo constitucional autónomo con universidad pública autónoma. Ciertamente, ambos poseen una serie de atributos similares, pero también diferencias notorias. Mientras en las universidades públicas autónomas sus autoridades académicas son designadas por sus propios órganos de gobierno, en los otros organismos, los designan uno o dos de los poderes del Estado.

Mientras las autoridades académicas no son susceptibles de juicio de responsabilidad política, sino que sus responsabilidades las conocen los órganos internos que señala la ley orgánica y sus reglamentos, en los otros organismos, a sus máximas autoridades sí se les puede seguir un juicio como el señalado.

En tanto que en las universidades públicas autónomas el ingreso, la promoción y la permanencia del personal que realiza las labores sustantivas de la institución — las académicas - los fija la propia institución, a través de estatutos y reglamentos que ella misma expide, en los órganos constitucionales autónomos, dichas reglas son determinadas principalmente por cuerpos externos a ellos, a través de leyes. ${ }^{23}$

Desde luego, las universidades públicas autónomas revisten relevancia constitucional. Por esta razón es que la propia ley fundamental señala sus características esenciales.

Hoy en día cumplir con el derecho a la información y el acceso a la documentación pública por parte de las universidades públicas autónomas, es una obligación constitucional y legal para éstas. Pero es algo más; es una responsabilidad ética, porque las universidades públicas deben ser y dar ejemplo de transparencia, la cual es, como ya afirmé, un principio propio de las democracias.

23 González Pérez, Luis Raúl y Guadarrama López, Enrique, op. cit., nota 1, pp. 29 , 30 y 36. 
Las universidades públicas son parte esencial de la conciencia crítica del país. En consecuencia, tienen que ser paradigma de transparencia.

4. En varias universidades el cuerpo legal que regula la transparencia y el acceso a la información pública es, debido a que la respectiva ley lo permite, un acuerdo del rector. No obstante, dicho cuerpo jurídico tiene como naturaleza ser una norma general, impersonal y abstracta, que se está refiriendo a dos preceptos constitucionales, que los está armonizando dentro del marco de la ley respectiva. En consecuencia, debe ser el Consejo Universitario el que expida el estatuto o reglamento correspondientes.

5. Varias de estas normas universitarias manifiestan que una de sus finalidades es la rendición de cuentas a la comunidad universitaria y a la sociedad. A pesar de que transparencia y acceso a la información son cuestiones diversas de la rendición de cuentas, es acertado asociarlas, en virtud de que están íntimamente relacionadas. La rendición de cuentas colabora a fortalecer la transparencia.

6. En los reglamentos y acuerdos respectivos de las universidades públicas autónomas prevalece, como debe ser, la regla general de la máxima transparencia y la mayor facilidad de acceso a su documentación pública. Con todo acierto estructuran sistemas para hacer compatibles esas finalidades, mandato del artículo 6o. constitucional y de las leyes de transparencia con otros derechos constitucionales, como son el derecho a la privacidad, a la intimidad, al honor, a la propia imagen y primordialmente con la autonomía universitaria, que es raíz, tronco, savia y alma de las universidades públicas autónomas. A estos aspectos regresaré con otras consideraciones.

7. Como regla general, y porque así lo disponen las normas constitucionales y las leyes respectivas, las universidades públicas autónomas publican o tienen en sus páginas electrónicas abundante información sobre ellas mismas, que incluyen los aspectos más diversos. El enunciado de los rubros en los reglamentos y acuerdos universitarios es muy amplio. En algunos casos se especifica qué información debe hacerse pública cada año sin necesidad de que nadie la solicite. Mientras más información se contenga en esos medios, se fortalece mejor la transparencia en la institución y podrá ser más expedita en contestar muchas de las solicitudes, porque sólo será necesario remitir con precisión al lugar donde dicha información puede ser localizada. Además, las personas pueden acostumbrarse a tener la cultura informática 
para que, antes de hacer una solicitud, revisen los libros o páginas electrónicas respectivas, con lo cual todos ganan.

8. En la mayoría de las universidades públicas autónomas existe una dependencia administrativa central que recibe diversas denominaciones, entre ellas unidad o coordinación de transparencia o de enlace, que es el vínculo entre las dependencias y el solicitante, es el órgano que realiza la recepción de la solicitud, su procesamiento, tramitación y notificación de la resolución.

El titular de la Unidad generalmente es designado por el rector, y suele depender de la Secretaría General. Considero que lo anterior constituye un buen sistema, expedito y ordenado, que contribuye a la eficacia y a la prontitud de las respuestas. Su función es esencialmente administrativa y ejecutiva de los criterios que establece el órgano colegiado denominado Comité.

9. Este último órgano recibe diversas denominaciones como Comité de Información, Comité de Resolución, Comité de Información de Acceso Restringido, Comité Clasificador de la Información Pública, cuyas funciones primordiales consisten en catalogar la información como reservada o confidencial en los términos de la ley expedida por el Poder Legislativo, y del reglamento o acuerdo universitario respectivos. Este Comité, además, emite los criterios para la clasificación y desclasificación de esa información reservada o confidencial, qué partes de los documentos se reservan, el plazo de la propia reserva y la autoridad responsable de su conservación, etcétera.

El Comité, como su propio nombre lo señala, es un órgano colegiado. Su labor no es administrativa, sino interpretativa de la norma en relación con la información reservada y confidencial. Es una labor delicada y de fino criterio universitario.

La regla casi general de las universidades públicas es que este Comité lo constituyan autoridades académico-administrativas, o sólo administrativas. De acuerdo con la Universidad, se integra por el rector, el secretario general, el contralor, el abogado general o director jurídico, el director del archivo, el tesorero, los directores de servicios estudiantiles, de recursos humanos o de planeación, etcétera.

En la integración de este Comité encuentro un problema, porque se le convierte en juez y parte, en virtud de que quienes lo integran pueden ser 
titulares de dependencias a las que se haya solicitado información y se haya negado; además, su imparcialidad puede ser cuestionada. Son las autoridades y funcionarios más importantes de la institución a quienes se les podría atribuir parcialidad o interés en no hacer público algún documento.

En este aspecto me preocupa que por la integración del Comité, las universidades pudieran perder demandas judiciales en su contra.

10. Unas pocas universidades, me parece, comparten este criterio y buscan nuevos derroteros para la integración de estos comités.

En un caso, es una Comisión Especial del Consejo Universitario, integrada por el rector o quien él designe, el contralor y el titular de la Unidad de Enlace, más consejeros universitarios. Sólo apunto que sería conveniente contar con algún abogado, porque en dicha Comisión es necesario el criterio jurídico.

En otro caso, se integra por tres comisionados propuestos por el rector y ratificados por el Consejo Universitario, quienes únicamente pueden ser destituidos por el propio Consejo Universitario, más dos nombrados por dicho Consejo entre sus miembros.

Se pueden contemplar otras posibilidades: una comisión presidida por el Defensor de los Derechos Universitarios, donde exista, más dos consejeros universitarios no autoridades, dos representantes del rector y dos profesores o investigadores eméritos del área jurídica, designados por el propio Consejo.

Las posibilidades para una buena y equilibrada integración de dicho Comité son diversas. Desde luego que la autoridad central de la Universidad necesita formar parte de la Comisión por su experiencia, y porque es quien conoce los problemas cotidianos que se presentan y los que se pueden presentar.

Este Comité debe convertirse realmente en un órgano garante de la transparencia y acceso a la documentación pública de las universidades públicas autónomas, que goce de independencia en el sentido que sus decisiones las alcance con libertad; es decir, sin estar subordinado a ninguna autoridad universitaria o externa, sino enmarcado únicamente dentro de la Constitución, la ley y el reglamento.

Un comité autónomo cobra importancia singular por otro aspecto al que me referiré posteriormente. 
11. Para asegurar la transparencia y el acceso a documentos públicos, los procedimientos deben ser rápidos y expeditos, y únicamente se debe cobrar el costo de su reproducción, si éste existe. La gran mayoría de las universidades públicas respetan estos dos principios.

Por el contrario, en algunos órganos constitucionales autónomos, no en las universidades públicas, conozco que los trámites son engorrosos y burocráticos, y solicitan un precio exagerado por entregar la documentación, como si se tratara de un negocio. Este aspecto vulnera y nulifica el derecho a la información.

12. Las leyes expedidas por los poderes legislativos, así como los reglamentos y acuerdos de las universidades públicas, en términos generales, cada día persiguen con mayor convicción el equilibrio entre transparencia y otros derechos fundamentales. Tal es el caso de la documentación confidencial tratándose de datos personales de los miembros de la comunidad universitaria, como son, asimismo, origen étnico, características morales y emocionales, domicilio particular, patrimonio propio o de los padres, religión, opiniones políticas, estado de salud, etcétera. Es decir, todo aquello que pueda afectar la intimidad, la privacidad o el honor de la persona.

No obstante, pueden darse excepciones en razón de fines estadísticos, científicos o de interés general, omitiéndose el nombre de la persona o datos que la puedan identificar, o por orden judicial.

13. En relación con los documentos calificados como información reservada, el catálogo suele ser amplio y, en general, es acertado aunque sí existen algunos problemas.

Como rubros acertados únicamente menciono algunos:

a) procedimientos de valoración académica, administrativa o laboral;

b) expedientes en trámite ante las comisiones del Consejo Universitario, Auditoría Interna u Oficina del Abogado General;

c) las opiniones, recomendaciones o puntos de vista del proceso deliberativo de los cuerpos colegiados hasta que no esté adoptada la decisión final; 
d) los expedientes ante el tribunal universitario o la comisión revisora, mientras se encuentre en trámite;

e) las investigaciones científicas y académicas en proceso;

f) aquella cuya difusión pueda poner en riesgo la vida, la seguridad o la salud de cualquier persona;

g) datos en los juicios en que la Universidad sea parte o tercero perjudicado, etcétera.

14. Existe un caso en el cual se señala que no es información reservada aquella relativa a una investigación grave de derechos humanos o conductas presuntamente constitutivas de delitos. Estoy de acuerdo. Es imposible que una universidad se convierta en cómplice de un delito.

15. Ahora bien, dicho catálogo de causales no debe contener reglas tan generales o abstractas que en ellas todo puede caber, por ejemplo:

a) información que tiene posibilidad de causar serio perjuicio a las actividades académicas, administrativas o de investigación. Es tan genérica que puede prestarse o ser pretexto para no proporcionar la información. Las causales deben ser precisas, porque son excepciones;

b) la que comprometa la seguridad o estabilidad financiera de la Universidad. No lo creo posible. Si en algo la Universidad tiene que ser transparente es en el manejo y destino de sus recursos, los cuales en gran proporción son públicos;

c) si se causa un daño o perjuicio irreparable al Estado por tratarse de información estratégica en materia de seguridad del propio Estado, seguridad pública o prevención del delito. Es información que una universidad pública no posee, a menos que se le encargue una investigación sobre dichos temas. Hasta ahora no conozco un caso parecido en nuestro país;

d) la que el Comité clasifique con ese rubro señalando su justificación. De nueva cuenta es tan genérica que resulta indebida.

Las universidades públicas deben ser muy puntuales en el establecimiento de las causales de información reservada: las que establece la ley respectiva, y únicamente agregar aquellas que son necesarias para proteger la autonomía universitaria. 
16. Desde luego que en lo relativo a información confidencial y reservada deben tenerse presente las normas correspondientes en cuerpos jurídicos, como el Código Civil, el Código de Comercio, la Ley Federal de Derecho de Autor y la Ley Federal de Propiedad Industrial.

17. En el aspecto de la información reservada deseo hacer énfasis en dos cuestiones en las cuales es indispensable lograr la compatibilidad entre la autonomía universitaria y el derecho a la información:

a) Información derivada de procesos deliberativos de cuerpos colegiados universitarios.

Esta información debe considerarse reservada, debido a que:

i. En la evaluación académica, la información está estrechamente vinculada con aspectos personales de quienes son valorados. Si se diera a conocer dicha información, podría dañarse la imagen y el honor de las personas evaluadas.

ii. Existe, además, el riesgo de que, al permitirse legalmente el acceso a los expedientes de los procesos deliberativos que contengan opiniones, recomendaciones, dictámenes o puntos de vista de los universitarios evaluadores, se genere que estos últimos no se sientan con plena libertad de expresión, y se comprometa su objetividad, en virtud de que, al ser sometidos al escrutinio público, podrían considerar que, de asumir determinada postura, en un futuro, se verían afectados personalmente o incluso laboralmente por la manifestación de sus ideas. Es decir, se corre el riesgo que la valoración académica no se lleve a cabo como debe ser por autocensura a la libertad de expresión. Téngase en cuenta que es una valoración que realizan los pares en relación con otros colegas.

b) Información derivada de procesos de designación de autoridades.

i. Algo similar a lo que señalé en el punto anterior sucedería en los órganos que designan autoridades universitarias, debido a que si, por ejemplo, se llega a conocer quiénes votaron y en qué sentido, se podría generar una polarización que llegara incluso a fracturar a la comunidad universitaria. Asimismo, se inhibiría la libre expresión de las opiniones. 
ii. En esta situación y en la mencionada en el punto anterior, lo conveniente es que, en todo caso, sea posible el acceso a la información derivada de los procedimientos y sus resultados finales, mas no así de los detalles de las deliberaciones y votaciones.

iii. En esa forma se haría compatible el acceso a la información con la autonomía universitaria, en virtud de que ésta implica, entre otros aspectos, como ya apunté, que la Universidad nombre a sus autoridades con plena libertad y de la mejor manera, de acuerdo con su orden jurídico.

El derecho constitucional de la autonomía universitaria es cien por ciento compatible con el de la transparencia y el acceso a la información pública. Los dos son especialmente valiosos. Los dos cumplen una función social. Lo único que hay que lograr, lo reitero, es su armonización.

18. Los reglamentos y acuerdos respectivos de las universidades públicas señalan que los recursos procesales internos que se pueden interponer a la decisión de negación de documentos se realiza ante el abogado general o el jefe del departamento o dirección jurídica para su resolución. Lo anterior no es correcto, porque se convierte a dicho funcionario en juez y parte, además de que su imparcialidad puede ser cuestionada.

Los recursos podrían presentarse ante el Comité de Información o de Acceso Restringido, órgano universitario, al que me referí en el punto 9, que debe gozar de independencia de criterio y decisión. Debe convertirse en órgano garante, tanto de la autonomía universitaria como del derecho a la información. Me inclino por esta posibilidad para no duplicar órganos universitarios que necesitarían apoyo administrativo. Para las universidades públicas el cumplimiento de la obligación constitucional del artículo 6o. no debe implicar mayor burocracia ni gasto excesivo. Se puede realizar con un costo pequeño.

19. Las responsabilidades y las sanciones al funcionario renuente a cumplir con las obligaciones que se derivan de los reglamentos y acuerdos universitarios de transparencia y acceso a la documentación pública, deben precisarse en esos propios cuerpos normativos. 
20. Un aspecto muy delicado en relación con la autonomía universitaria versa sobre si la decisión del Comité de Transparencia de la Universidad Pública puede ser impugnada ante un órgano externo a la propia Universidad y de carácter no jurisdiccional.

La contestación es no, porque se vulnerarían varios de los elementos que integran la autonomía universitaria.

A nivel federal no existe problema alguno, debido a lo establecido en los artículos 3o., fracción IX, y 61 de la Ley Federal de Transparencia y Acceso a la Información Pública Gubernamental.

Con base en esos artículos, el IFAI no es competente para conocer ninguna impugnación de esa naturaleza referida a universidades federales públicas y autónomas, y así acontece en la realidad. Por ejemplo, ante el IFAI se han presentado dos recursos de impugnación - los expedientes 570/04 y 225/06 - respecto a negativas de la Universidad Nacional Autónoma de México a entregar documentación, cuya publicidad hubiera lesionado su autonomía. En ambas ocasiones el IFAI se declaró incompetente.

21. Sin embargo, en algunas leyes de los estados sí se acepta la competencia del Instituto, Consejo o Comisión de Transparencia y Acceso a la Información del estado para conocer y resolver sobre la negativa del comité respectivo de la universidad pública autónoma, lo cual interfiere y vulnera la autonomía si se refiere a evaluaciones académicas y al proceso de designación de sus autoridades.

Véase, entonces, la especial importancia que reviste que esos comités gocen de autonomía plena y que no pueda considerarse que son juez y parte, aunque necesariamente algunos de sus miembros sean autoridades universitarias o representantes de éstas.

22. Desde luego que un solicitante de información podrá recurrir a la autoridad jurisdiccional correspondiente para defender el derecho constitucional que considera que se le ha lesionado. No obstante, el juez constitucional también está obligado a respetar el derecho constitucional de la autonomía universitaria de acuerdo con el artículo 3o., fracción VII. 
23. Las universidades públicas deben continuar dialogando para establecer criterios comunes en estas materias; así lo han hecho y ello ha sido benéfico para las instituciones, conservando su plena libertad al momento de establecer su propio reglamento.

En todos los temas el intercambio de opiniones y el señalamiento de criterios comunes ha sido muy provechoso. Las universidades públicas persiguen los mismos fines: cumplir con sus funciones académicas en la mejor forma posible, al servicio de la nación, y con una visión y proyección social. 